\title{
Crítica a uma apropriação unilateral de tecnologia: a análise do conceito de tecnologia social
}

\section{Critic to a unilateral appropriation of technology: the analysis of the concept of social technology}

\author{
Rafael Rodrigo Mueller ${ }^{1}$
}

Deise Luiza Ferraz ${ }^{2}$

\begin{abstract}
Resumo
Nosso objetivo, nesse ensaio, é discutir a partir de uma abordagem marxianalukacsiana, a apropriação unilateral da aplicação tecnológica da ciência que é realizada, tanto por estudiosos voltados à produção de tecnologias convencionais, quanto por teóricos que as refutam em nome da construção de uma nova tecnologia, dita tecnologia social. Assim, argumentamos que a tecnologia não é em si geradora das desigualdades econômicas que culmina na denominada exclusão social, tampouco, uma inclusão demandaria a refutação do conhecimento científicotecnológico acumulado historicamente. Ao identificarmos possíveis limitações teóricas concernentes à "tecnologia social", e que, segundo a sua mesma matriz teórica, se contrapõe a uma "tecnologia convencional", pretendemos expor a necessidade de uma apropriação de tecnologia que comporta em sua base epistemológica a sua vinculação direta à ontologia do ser social, conforme Marx e Lukács.
\end{abstract}

Palavras-Chave: Ontologia do ser social. Tecnologia Social. Tecnologia Convencional.

\begin{abstract}
Our goal in this essay is to discuss, from a Marxian-Lukacsian approach, the unilateral appropriation of technological application of science that is carried out as by academics focused to the conventional production technologies as by theorists that deny in the name of construction of a new technology, called social technology. Thus, we argue that the technology in itself is not a producer of an economic inequality that culminates in the so-called social exclusion and an inclusion would require a refutation of scientific-technological knowledge accumulated historically. By identifying possible theoretical limitations relating to 'social technology' and that according to its theoretical matrix, it is opposed to a 'conventional technology', we intend to show the necessity of an appropriation of technology that has in its epistemological basis its the direct connection to the ontology of the social being according to Marx and Lukács.
\end{abstract}

Keywords: Ontology of social being. Social Technology. Conventional Technology.

\footnotetext{
${ }^{1}$ Doutor em Educação. Professor do Programa de Pós-Graduação em Organizações e Desenvolvimento da UNESC. E-mail: rrmueller@gmail.com

${ }^{2}$ Doutora em Administração. Professora Adjunta no Departamento de Ciências Administrativas da Faculdade de Ciências Econômicas da Universidade Federal de Minas Gerais. Email:deiseluizaferraz@gmail.com..
} 


\section{Introdução}

O Brasil alcançou, em 2011, a colocação de sexta maior potência econômica do mundo, entretanto, como demonstram os relatórios da Comissão Econômica para América Latina e Caribe, segue sendo um dos países com pior distribuição de renda (índice Gini, no ano de 2009 , foi igual a 0,576 ), e possuindo cerca de $18 \%$ da população vivendo com menos de dois dólares por dia. A preocupação com a diminuição da pobreza no Brasil tornou-se, na última década, programa de governo, cujo lema "País Rico é País Sem Pobreza" é o principal exemplar da tentativa de alcançar as Metas do Milênio estipuladas pela Organização das Nações Unidas.

Uma das formas de concretização dos programas de governo são as políticas públicas, das quais destacamos as políticas sociais de promoção, como as Políticas Públicas de Geração de Trabalho e Renda (PPGTR). Por meio da ação do Ministério do Trabalho e do Emprego (MTE) efetivam-se distintos programas, conforme público alvo. No que tange ao estrato populacional pauperizado, denominado como superpopulação consolidada, as políticas sociais de promoção são aquelas vinculadas à Economia Solidária (ES), coordenada pela Secretária Nacional de Apoio à Economia Solidária (Senaes).

O levantamento efetuado, no ano de 2008, pelo Senaes, informa que a política investiu cerca de 58 milhões de reais e atendeu aproximadamente 1 milhão e 700 mil pessoas. Contudo, os resultados referentes à melhoria na renda dos trabalhadores envolvidos não permitem, até o momento, identificar uma redução significativa no processo de pauperização desse estrato populacional. Cria-se, assim, o fato para a retroalimentação do senso comum de que a destinação de verbas públicas para as atividades do projeto é um gasto social sem retorno. $\mathrm{Na}$ tentativa de romper com esse círculo vicioso, os gestores públicos elaboraram alguns programas de apoio aos empreendimentos, dos quais destacamos o chamado aos intelectuais brasileiros para a construção de Tecnologias Sociais (TS).

É preciso incentivar o desenvolvimento e a disseminação de conhecimentos sobre as potencialidades e desafios dos Empreendimentos Econômicos Solidários para que a sociedade e o Estado brasileiro compreendam e ampliem o apoio a essas iniciativas como alternativa de desenvolvimento com inclusão social por meio da geração de trabalho e renda. Os estudos e pesquisas são necessários também para subsidiar os processos de 
formulação de políticas públicas para a Economia Solidária. Além disso, é necessário desenvolver e disseminar tecnologias sociais apropriadas a esses empreendimentos como condição fundamental para a viabilidade de suas atividades econômicas (MTE, s/p). .

Essa chamada ressoou na academia brasileira e, na última década, foram realizadas inúmeras discussões em torno das possibilidades e limitações para desenvolver tecnologias sociais. A principal limitação indicada por autores como Dagnino, Brandão e Novaes (2004) é a impossibilidade do surgimento de tecnologias que atendam às demandas das populações pauperizadas derivarem do conhecimento que foi desenvolvido com uma orientação para a valorização do valor, conhecimento esse convencionado pelos autores como Tecnologias Convencionais (TC). A discussão dos autores, apesar de trazer relevantes contribuições para o debate, indica a necessidade de um recomeçar, no campo científico e tecnológico, para os intelectuais preocupados com um desenvolvimento social equânime. De acordo com os estudos desenvolvidos por Dagnino, Brandão e Novaes (2004), a tecnologia convencional, a tecnologia que hoje existe, que a empresa privada utiliza, não é adequada para a inclusão social (IS).

Concordamos com os autores sobre o fato de que o conhecimento e a tecnologia desenvolvidos para uso das empresas privadas não são adequados para a inclusão social, mas a inadequação não reside, imediatamente, na natureza do conhecimento e da tecnologia e, sim, no uso que se faz dela, de modo que não carecemos de um recomeço, mas de um reposicionamento frente à teleologia do conhecimento desenvolvido ao longo da história.

Desse modo, com a elaboração deste ensaio, tencionamos discutir, a partir de uma abordagem marxiana-lukacsiana, a apropriação unilateral da aplicação tecnológica da ciência que é realizada, tanto por estudiosos voltados a produção de tecnologias convencionais quanto pelos teóricos que as refutam em nome da construção de uma nova tecnologia. Assim, argumentaremos que o conhecimento não é em si gerador das desigualdades econômicas que culmina na denominada exclusão, tampouco uma inclusão demandaria a refutação do conhecimento científico-tecnológico, acumulado historicamente. Para isso, este texto está estruturado de modo que, no primeiro item, dissertaremos acerca da concepção Marxiana-Lukacsiana acerca da tecnologia e de suas implicações para a constituição do ser social. No segundo item, analisamos a apropriação unilateral 
fatalista de tecnologia, característica e necessária ao modo de produção vigente, dialogando com autores, especificamente, Dagnino, Brandão e Novaes (2004), que desenvolvem um marco teórico acerca da TS em contraposição a TC. No terceiro item, sustentados na discussão de Marx e Lukács acerca do desenvolvimento dos meios de trabalho (conhecimento e tecnologia), enquanto constantes antropológicas que guardam em si possibilidades que vão além das teleologias que as originaram, demonstraremos que não há tecnologia que não seja social, bem como, que a superação das desigualdades sociais não passa necessariamente pelo descarte da produção intelectual humana, mas pela superação das contradições que as gestaram. Desse modo, nas considerações finais, problematizaremos tanto as possibilidades ensejadas para o termo 'tecnologia social' e sua antítese a 'tecnologia convencional', quanto as consequências sociais de um construto teórico ser apropriado unilateralmente e suas implicações para a produção de novos conhecimentos.

\section{A Tecnologia na concepção Marxiana-Lukacsiana}

Não é nosso objetivo, no presente artigo, apresentar uma exaustiva discussão sobre a tecnologia nos estudos de Marx e Lukács, sobretudo porque ela não era a preocupação central dos autores em questão, apesar de o desenvolvimento do conhecimento e da aplicabilidade dele fazerem parte constituinte do processo de trabalho. Assim, não encontramos nem em Marx nem em Lukács, uma teoria da tecnologia, embora ambos demonstrem que na ontologia do ser social a tecnologia se apresenta como elemento necessário. A tecnologia apresenta-se enquanto elemento necessário porque encerra em si o conhecimento da natureza e a forma de agir sobre ela. O pôr teleológico em Lukács significa uma ação orientada para um fim previamente ideado, ou seja, o que denominamos trabalho.

\footnotetext{
O que caracteriza e determina a especificidade da atividade humana é a transformação da atividade natural em uma 'atividade posta', ou seja, é a configuração objetiva de um fim previamente estabelecido - o pôr teleológico. O trabalho é a unidade entre o pôr efetivo de uma objetividade e a atividade ideal prévia diretamente regida e mediada por uma finalidade específica (LUKÁCS, 2010, p. 24).
}

Marx (1996) ao discutir o trabalho enquanto elemento fundante da ontologia 
humana apresenta-o como um processo. A atividade orientada a um fim opera-se em um objeto do trabalho e a transformação desse objeto do trabalho em produto do trabalho (antes ideado) necessita da aplicação de meios de trabalho. Para Marx (1996, p. 300), "o meio de trabalho é uma coisa ou um complexo de coisas que o trabalhador coloca entre si mesmo e o objeto de trabalho e que the serve como condutor de sua atividade sobre esse objeto [...]".

Conforme Lukács (s/d, p. 18):

\begin{abstract}
A posição da finalidade tem origem em uma necessidade sócio-humana; mas, para que ela se torne uma autêntica posição de um fim, é necessário que a busca dos meios (isto é, conhecimento da natureza) tenha chegado a um certo nível, adequado a esses meios. [...] Em suma, o ponto no qual o trabalho se liga ao pensamento científico e ao seu desenvolvimento é, do ponto de vista da ontologia do ser social, exatamente aquele campo por nós designado como busca dos meios.
\end{abstract}

Lukács (s/d, p. 19), após algumas considerações sobre o pensamento de Hegel, afirma sua concordância com a afirmação desse autor sobre "a duração mais longa dos meios relativamente aos fins imediatos". Nesse caso, é possível considerar que essa menor perenidade resulta em uma ampliação das possibilidades provenientes da causalidade previamente posta.

\begin{abstract}
Aqui só podemos observar provisoriamente que qualquer conhecimento e utilização dos nexos causais - vale dizer, qualquer posição de uma causalidade real - sempre se insere no trabalho como meio para um único fim, mas tem objetivamente a propriedade de ser aplicável a outro distinto, e até a algo que a primeira vista pareça completamente heterogêneo (LUKÁCS, s/d, p. 21)
\end{abstract}

Deste modo, o que salienta Lukács é que a produção da tecnologia apresenta-se na imediaticidade da realidade concreta, em termos de um conhecimento adequado para a finalidade existente, a despeito de guardar em si a potencialidade de satisfação de outras finalidades. A transformação dessa potencialidade segue o processo do desenvolvimento do conhecimento sobre ela, que pode ser efetuada tanto pela afirmação quanto pela negação, segundo num movimento dialético. Em suma, Lukács (s/d) afirma que no processo dos pores teleológicos, os meios desenvolvidos para alcançar os fins permanecem para além da objetivação da finalidade. Eles são, portanto, portadores da possibilidade de atender a outras teleologias não imaginadas quando de seu desenvolvimento inicial. Assim, o acúmulo de conhecimento historicamente produzido se constituiu mediante

Cad. de Pesq. Interdisc. em Ci-s. Hum-s., Florianópolis, v.14, n.104, p.131-150, jan/jun 2013 
os mais diversos fins estabelecidos, nas mais diversas formas societárias, isso significa que o conhecimento produzido, através da busca dos meios adequados para atingir os diversos fins historicamente estabelecidos, não é desconsiderado para a constituição de novos objetivos. É por isso que o conhecimento mais adequado, que fundamenta os meios (utensílios, etc.) é, muitas vezes, para o ser social, mais importante do que a satisfação daquela necessidade (finalidade) (LUKÁCS, s/d, p. 19).

A discussão de tecnologia, em Lukács ( $\mathrm{s} / \mathrm{d}$ ), pode ser considerada sobre dois aspectos, portanto, o da instância da causalidade e o da teleologia. A causalidade está para o meio, enquanto que a teleologia para o ser social. Há uma relação condicionante entre elas. O conhecimento das relações causais, derivado das qualidades da natureza, permite ao homem o pôr teleológico específico ao mesmo tempo em que condiciona novos pores teleológicos com o conhecimento originado do primeiro.

Nos Grundrisse, Marx (2011) destaca o papel da ciência enquanto fator catalisador do desenvolvimento das forças produtivas sociais.

\begin{abstract}
A natureza não constrói máquinas nem locomotivas, ferrovias, telégrafos elétricos, máquinas de fiar automáticas etc. Elas são produtos da indústria humana; material natural transformado em órgãos da vontade humana sobre a natureza ou de sua atividade na natureza. Elas são órgãos do cérebro humano criados pela mão humana; força do saber objetivada. [...] as forças produtivas da sociedade são produzidas, não só na forma do saber, mas como órgãos imediatos da práxis social; do processo real da vida (MARX, 2011, p. 589).
\end{abstract}

Com essa citação de Marx (2011), concedemos materialidade ao meio discutido por Lukács. Em Marx, a ciência é incorporada ao processo de produção por ser a forma de conhecimento da natureza ou do objeto do trabalho, uma forma que teleologicamente visa desenvolver as forças produtivas sociais. É prudente destacarmos que esse desenvolvimento não pode ser confundido com o interesse do capital pelo aumento da produção de mais valia. A capacidade humana de desenvolver o que chamamos de conhecimento científico e utilizá-lo no processo de trabalho com a finalidade de satisfazer necessidades humanas, por si só, não é capacidade de produção da exploração do homem pelo homem. A despeito de Marx e Engels (2010, p. 44), já em 1848, terem admitido todo o potencial criado em prol do desenvolvimento das forças produtivas pelo modo de produção capitalista, "a 
burguesia, em seu domínio de classe de apenas um século, criou forças produtivas mais numerosas e mais colossais do que todas as gerações passadas em seu conjunto".

Esse poder catalisador do modo de produção capitalista é explicado por Marx n'O Capital, quando o mesmo menciona o mecanismo da concorrência enquanto potencializador da inovação tecnológica no processo produtivo com a finalidade de redução do tempo socialmente necessário para a produção:

Tal não é também de modo algum a finalidade da maquinaria utilizada como capital [...] ela se destina a baratear mercadorias e a encurtar a parte da jornada de trabalho que o trabalhador precisa para si mesmo, a fim de encompridar a outra parte da sua jornada de trabalho que ele dá de graça para o capitalista. Ela é meio de produção de mais-valia (MARX, 1996, p. 05).

Resta claro que, sob o modo de produção capitalista, onde o meio de trabalho é de propriedade privada, seu uso visa atender necessidades privadas e, assim, a tecnologia, tal como a ciência - enquanto um processo de trabalho - também está para o homem, numa relação de estranhamento. Com isso, a colaboração da ciência volta-se para a valorização do valor. No caso das ciências administrativas, para o aumento da produtividade do trabalho. Entretanto, na elaboração de conhecimentos aplicados, tecnologias, as Ciências Administrativas, assim como todas as outras áreas científicas, operam tanto quanto intensificadoras das contradições quanto como campo de possibilidades de criação para a superação das mesmas.

Nesse sentido, as tecnologias desenvolvidas pelas universidades aparecem, na imediaticidade das relações sociais, enquanto tecnologias excludentes, exploratórias, controladoras, ou, como prefere Novaes (2004), tecnologias convencionais.

A partir dessa discussão apresentada nesse item sobre o momento ontológico da tecnologia, discutiremos a seguir a apropriação unilateral sobre a tecnologia desenvolvida pelos estudiosos da economia solidária, preocupados com a inclusão social por meio dos empreendimentos autogestionários. 


\section{Tecnologia social $x$ tecnologia convencional: 0 pressuposto da unilateralidade}

Para fins analíticos, iniciaremos este item explicitando os dois termos desenvolvidos por Dagnino (2004), os quais pretendemos analisar verificando suas limitações e possíveis contribuições, especialmente do primeiro, para os empreendimentos ditos autogestionários, quais sejam: a tecnologia social e a tecnologia convencional.

O autor não se propõe a conceituar os termos em questão, mas, sim, caracterizá-los a partir de suas funções sociais e contribuições para determinados coletivos, nesse caso, a tecnologia convencional (TC) e a tecnologia social (TS) se caracterizam da seguinte forma:

\begin{tabular}{|c|c|}
\hline Tecnologia Convencional (TC) & Tecnologia Social (TS) \\
\hline $\begin{array}{l}\text { Segmentada: pois o controle sobre a } \\
\text { mesma não é exercido pelo seu produtor }\end{array}$ & \\
\hline $\begin{array}{l}\text { Alienante: porque não permite o } \\
\text { desenvolvimento de todo o potencial de } \\
\text { seu produtor. }\end{array}$ & $\begin{array}{l}\text { Possibilita a liberação de todo potencial e } \\
\text { criatividade de seus produtores. }\end{array}$ \\
\hline $\begin{array}{l}\text { Hierarquizada: pois exige a figura do } \\
\text { proprietário-chefe } \quad \text { em } \\
\text { burocráticos. }\end{array}$ & $\begin{array}{l}\text { Por ser concebida para atuar fora da } \\
\text { lógica "patrão-empregado", não é } \\
\text { discriminatória. }\end{array}$ \\
\hline $\begin{array}{l}\text { Prioriza a produtividade em detrimento a } \\
\text { força de trabalho utilizada para a } \\
\text { produção. }\end{array}$ & $\begin{array}{l}\text { Adaptada para atuar em um contexto } \\
\text { reduzido em termos financeiro e físico. }\end{array}$ \\
\hline $\begin{array}{l}\text { Está orientada a partir do mercado } \\
\text { externo de alta renda. }\end{array}$ & $\begin{array}{l}\text { Sua orientação está voltada para o } \\
\text { "mercado interno de massa" (DAGNINO, } \\
2004 \text {, p. 193). }\end{array}$ \\
\hline $\begin{array}{l}\text { Concebida e utilizada por grandes } \\
\text { empresas dos países desenvolvidos. }\end{array}$ & 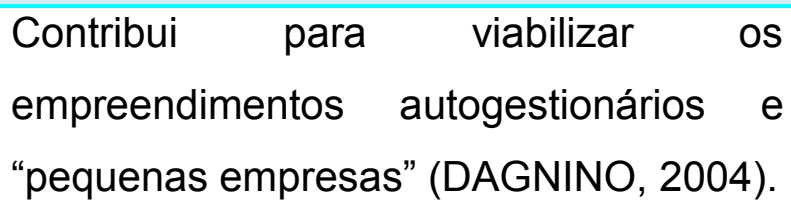 \\
\hline
\end{tabular}

Tabela 1: A tecnologia convencional (TC) e a tecnologia social (TS).

Fonte: Próprio autor. 
Convém identificarmos que, segundo a análise do autor, essas características são inerentes a sua constituição, ou seja, tais características estão situadas na essência de cada uma delas. Esse fato é de suma importância para expormos as limitações da visão unilateral atribuída à tecnologia. Ao contrapor as TS em relação às TC, Dagnino (2004) cria uma polarização conceitual sobre o desenvolvimento tecnológico e, consequentemente, sobre a produção do conhecimento, descaracterizando destarte $\circ$ trabalho universal ${ }^{3}$ enquanto atividade essencial do homem em seu desenvolvimento histórico.

Quanto às características expostas para ambas as manifestações de tecnologia desenvolvidas, pretendemos nos deter em algumas limitações assim colocadas para a TC e para TS, respectivamente:

\subsection{Alienante versus libertadora}

Conforme Dagnino (2004, p. 192), a TC é alienante, "pois não utiliza a potencialidade do produtor direto. Mas a criatividade, a potencialidade do produtor direto que a TC inibe pode ser liberada no interior de um empreendimento autogestionário". Primeiro, necessitamos considerar que a discussão da TC enquanto alienante necessita ser desenvolvida distintamente do qualitativo criativo.

De fato, a alienação não se constitui a partir da utilização da TC, mas, sim, a partir da apropriação privada dos meios de produção e da divisão do trabalho.

Somente a produção capitalista transforma o processo produtivo material
em aplicação da ciência à produção - em ciência, posta em prática, mas
somente submetendo o trabalho ao capital e reprimindo o próprio
desenvolvimento intelectual e profissional (MARX, 1980, p. 164) [grifo
nosso].

No que se refere ao tolhimento da criatividade dos produtores e trabalhadores a partir da utilização da TC, mesmo considerando uma real orientação da produção do conhecimento voltada à valorização do valor, onde centros de pesquisa públicos e privados contribuem para o desenvolvimento das forças produtivas do capital, isso não necessariamente irá limitar o uso por parte deste último, da criatividade humana, sendo esta última um dos fatores fundamentais para o processo de implementação

\footnotetext{
${ }^{3}$ Marx (2008), no livro O Capital vol. III, tomo IV, esclarece que o trabalho universal está diretamente relacionado à capacidade de racionalizar inerente ao ser social, no que diz respeito a inovar constantemente a base material da qual produz a sua existência.
}

Cad. de Pesq. Interdisc. em Ci-s. Hum-s., Florianópolis, v.14, n.104, p.131-150, jan/jun 2013 
de inovação no seio da produção. Conforme Tauile (2001, p. 150),

\begin{abstract}
O engajamento dos trabalhadores e sua importância para o bom desempenho do processo produtivo caracteriza, até certo ponto, uma "subversão" da tradicional tendência do capitalismo moderno de alienar o trabalhador do processo de produção, pela separação hierárquica entre as atividades de execução e concepção. A experiência da Toyota ilustra bem este ponto. Em 1960 iniciou-se, naquela empresa, um programa de sugestões por parte dos trabalhadores, para melhorar e aperfeiçoar os produtos que produziam e os processos produtivos nos quais estavam engajados. Segundo dados da própria empresa, no primeiro ano, foram 9 mil sugestões, com uma média anual de uma sugestão por trabalhador, sendo que $39 \%$ delas foram implementadas. Essa atividade, no ano de 1982, atingiu resultados impressionantes. Ao todo, foram 1.905 .642 sugestões, com uma média de 38,8 sugestões por empregado, sendo que $95 \%$ delas (praticamente todas) foram implementadas.
\end{abstract}

As barreiras muito bem delimitadas entre trabalho manual e intelectual são reduzidas até um ponto em que não comprometam o controle da força de trabalho, necessária ao processo de valorização do valor, por intermédio da inserção de tecnologias de gestão (orgware) que influem diretamente sobre o comportamento dos trabalhadores envolvidos nas etapas constituintes do processo de rotação do capital.

Além do que, não há como assegurar que, na constituição e utilização das TS, todo o potencial de criatividade dos produtores e trabalhadores envolvidos seja liberado, pois isso demandaria, primeiramente, uma "educação tecnológica" para todo o coletivo dos empreendimentos autogestionários. Caso contrário, a produção da TS estaria controlada por um grupo seleto de "tecnocratas", que consultaria o coletivo desprovido de conhecimento necessário para uma real contribuição para o desenvolvimento dos referidos empreendimentos.

\title{
3.2. Hierarquizada versus não-discriminatória
}

De acordo com Dagnino (2004, p. 192), a TC é hierarquizada porque "ao não permitir o controle do produtor direto sobre o processo de trabalho, torna sempre necessário um patrão, um capitalista, um chefe, um capataz, ou, mais modernamente, um engenheiro". E nesse caso, "só ele detém o controle sobre a totalidade dos processos de produção, de manutenção, de concepção" (idem). Certamente, a partir do momento em que o modo de produção capitalista exige, para o seu próprio desenvolvimento, uma implementação constante de ciência e 
tecnologia, ou, mais propriamente, a "aplicação tecnológica da ciência" (MARX, 2011), a figura do administrador, seja ele o patrão, o gerente ou o engenheiro, se faz necessária tanto quanto o controle sobre os meios de produção privados exige a divisão entre trabalho intelectual e manual.

Novamente enfatizamos que sem uma educação tecnológica implementada para todos os atores envolvidos no desenvolvimento dos empreendimentos ditos autogestionários, não há como impedir a reprodução de comportamentos oriundos da utilização de TC na produção capitalista, observados, por exemplo, em certos casos de fábricas recuperadas pelos trabalhadores e em empreendimentos populares, conforme Lima (2007). Destarte, não será certamente a mera produção e utilização de tecnologia que irá garantir uma possível autogestão, de acordo com Guillerm e Bourdet (1976).

\subsection{Orientação das empresas para a produtividade e o mercado externo de alta renda versus orientação dos empreendimentos autogestionários para a ocupação da força de trabalho e para o mercado interno de massas}

Dagnino (2004, p. 191) afirma que "a utilização da TC implica uma condição de desvantagem inerente para o pequeno produtor e é quase impedimento para a sustentabilidade do empreendimento - [...] - autogestionário". De fato, premido pela realidade concreta do modo de produção vigente, não há como o pequeno produtor, esteja ele em um empreendimento autogestionário ou em uma pequena empresa, contornar a lei da concorrência capitalista, onde o desenvolvimento das forças produtivas está diretamente relacionado à apropriação de ciência e tecnologia. Esses empreendimentos produzem para os vendedores da força de trabalho, logo, precisam operar dentro da média de trabalho socialmente necessário e isso somente é possível ou usando a tecnologia comum ao setor ou superexplorando outros trabalhadores. Nesse caso, não há como considerar que a mera apropriação de TS por parte desses empreendimentos poderia de alguma forma, dentro da realidade atual, invalidar a lei do valor e por fim à concorrência.

Analisando uma das características da TC, Dagnino (2004, p. 191-192) afirma que sua "cadência de produção é dada pela máquina, e não pelo trabalhador". Logo adiante diz que esta possui "controles coercitivos que diminuem sua produtividade" e que necessariamente o trabalhador irá se rebelar contra essa condição, o que irá

Cad. de Pesq. Interdisc. em Ci-s. Hum-s., Florianópolis, v.14, n.104, p.131-150, jan/jun 2013 
gerar um aumento dos custos de produção. Tanto o ritmo que a máquina imprime ao processo de produção quanto o controle que exerce sobre a força de trabalho não são "poderes" inerentemente vinculados à TC, mas, sim, a sua submissão aos objetivos da produção capitalista, pois se a tecnologia "impõe o ritmo" da produção e exerce "controle sobre a mesma", então se pode afirmar que ela é na verdade um ente vivo e com consciência, o que consideramos um possível "fetiche da tecnologia". O que, em última instância, impõe o ritmo e o controle é a teleologia do capitalista proprietário da tecnologia e submetido à lei da concorrência.

O autor considera como uma das características da TS, a de ser orientada para o mercado interno de massa, em detrimento a TC estar orientada para o mercado externo de massa. No que implica de fato se a tecnologia utilizada contribui para um mercado de massa interno ou externo se o mercado, objetivamente falando, está subsumido ao processo de valorização do valor, onde todas as relações, inclusive as que ocorrem no mercado, estão condicionadas pelos ditames do capital? Ao afirmar que a TS pode contribuir para o mercado interno de massa é afirmar a estrutura produtiva característica do sistema taylorista-fordista, transpondoo em uma escala reduzida: "o mercado interno". Portanto, o que difere a TS da TC se ambas estão orientadas ao mercado, independente do contexto em que se encontram?

Ademais, questionamos como as TS garantiriam uma produtividade necessária para abastecer o mercado interno de massa sem incutir nas mesmas características impostas à TC, as quais garantem o tempo de trabalho socialmente necessário à produção capitalista.

Segundo Dagnino (2004), a impossibilidade do desenvolvimento de tecnologias de inclusão social (IS) é posta como uma incapacidade das instituições universitárias e de pesquisa. Certamente não desconsideramos que há um número maior de pesquisadores dedicados a firmar compromisso com o setor privado do que com a sociedade em geral, todavia, não é possível afirmar que disso decorre uma capacidade existente distinta e não realizada: a TS. Sendo que essa condição nos impõe um novo questionamento: é possível a existência de TS que permita a auto-sustentabilidade dos empreendimentos autogestionários, tal como apresentada pelo autor, em concomitância com a TC? 


\section{Crítica a uma apropriação unilateral da tecnologia a partir da concepção Marxiana-Lukacsiana}

O desenvolvimento de uma concepção de tecnologia com aporte teórico marxiano-lukácsiano se dá a partir de uma necessária desmistificação e limitação, em termos de apropriação, da obra de Marx por Dagnino, Brandão e Novaes (2004), onde estes afirmam que há um determinismo tecnológico no marxismo "oficial". Distantes da apropriação marxiana acerca das aplicações tecnológicas da ciência, ${ }^{4}$ os autores reduzem a leitura de Marx a uma leitura de alguns autores que interpretaram Marx, ou seja, Marx seria idêntico ao marxismo "oficial". Como forma de reapropriarmos a leitura marxiana sobre ciência e tecnologia, utilizamos da apropriação lukacsiana que busca estabelecer o construto marxiano tendo em vista o desenvolvimento da ontologia do ser social. Nesse caso, tanto Marx quanto Lukács, de forma alguma, podem ser relacionados a um suposto "determinismo tecnológico", 5 principalmente se considerarmos que ambos se apropriaram da realidade a partir do método materialista histórico, contrário a qualquer forma de teleologia impingida à história. Além do fato de que, toda e qualquer forma de discussão dicotômica, aqui nesse caso "tecnologia social versus tecnologia convencional", não permite o acesso à totalidade histórica necessária para compreender as implicações sociais da tecnologia em sua relação com a constituição do ser social e, de forma particular, no modo de produção capitalista.

Primeiramente, a tecnologia é inerente à constituição do homem enquanto ser

\footnotetext{
${ }^{4}$ De acordo com Marx (2011, p. 583) [grifo nosso], "o desenvolvimento pleno do capital só acontece ou o capital só terá posto o modo de produção que lhe corresponde - quando o meio de trabalho é determinado como capital fixo não só formalmente, mas quando tiver sido abolido em sua forma imediata, e o capital fixo se defrontar com o trabalho como máquina no interior do processo de produção; quando o processo de produção em seu conjunto, entretanto, não aparece como processo subsumido à habilidade imediata do trabalhador, mas como aplicação tecnológica da ciência. Por isso, a tendência do capital é conferir à produção um caráter científico, e o trabalho direto é rebaixado a um simples momento desse processo".

${ }^{5}$ Convém destacarmos que nem mesmo autores não-marxistas corroboram com a ideia de que haveria um determinismo tecnológico em Marx, vide o item 1.2 da obra de Rosenberg (2006). Há ainda aqueles que, a partir de uma concepção filosófica apoiada na ontologia do ser social, como Vieira Pinto (2005), descartam igualmente tal ideia e apontam para uma possível "visão ingênua" sobre a tecnologia atual que não privilegia uma tensão dialética, desconsiderando as contradições do modo de produção capitalista: "desde o início de nossas reflexões excluímos, por ingênua, toda e qualquer espécie de consideração que, de alguma força, tende a privilegiar a época atual, nela fundando concepções sobre o significado da técnica, como se só agora estas especulações se tivessem tornado possíveis e fossem justificadas por motivo do tipo particular de procedimentos tecnológicos atualmente em uso" (VIEIRA PINTO, 2005, p. 142).
}

Cad. de Pesq. Interdisc. em Ci-s. Hum-s., Florianópolis, v.14, n.104, p.131-150, jan/jun 2013 
social: é sua parte integrante e imprescindível, e os produtos advindos da aplicação tecnológica da ciência acumulados na história humana constituem os nexos causais que incidem sobre a realidade concreta. Isso significa que, por mais que um construto tecnológico se desenvolva a partir de prévia-ideação (objetivo) dentro de um contexto histórico específico, ele sempre estará relacionado à totalidade histórica, sendo determinado por ela e determinando-a igualmente. Ou seja, por mais inovadora que possa parecer toda e qualquer tecnologia desenvolvida, esta só se constitui a partir de uma base de conhecimentos científico-tecnológicos acumulados no decorrer da história humana, nunca para além desta: toda a tecnologia de uma dada época só se desenvolve a partir de uma base concreta material previamente existente. Apesar de essa discussão parecer óbvia e que grande parte dos autores que tratam do tema tecnologia formalmente corroborarem com tais afirmações, estas não constituem a base conceitual para a antítese "tecnologia social versus tecnologia convencional", conforme pretendemos demonstrar no decorrer de nossa análise.

Conforme o construto teórico marxiano-lukacsiano, pode-se questionar o próprio termo "tecnologia social": como a tecnologia não seria "social" se ela só se constitui a partir de e é parte integrante do "ser social"? Mesmo que a intenção dos autores, ao desenvolverem esse termo, fosse a ideia de uma tecnologia que não estivesse a serviço direto das empresas, enquanto tecnologia desenvolvida para a produção capitalista, mas, sim, para o atendimento das necessidades produtivas de empreendimentos coletivos solidários, a tecnologia existente é uma só, submetida às circunstâncias históricas de uma dada época, sua organização política e social, logo, a tecnologia atual é fruto do conhecimento acumulado historicamente pelo modo de produção capitalista, destarte, a sua constituição e utilização estarão necessariamente submetidas a lógica da valorização do valor. Negar o potencial existente na aplicação tecnológica da ciência atual é negar toda a potencialidade contida no ser humano, mesmo que os objetivos colocados pelo capital sejam ontologicamente anti-humanos. Nesse caso, ao considerarmos a possibilidade de constituição de uma tecnologia a serviço de empreendimentos coletivistas e no intuito de uma inclusão social, esta só pode ser pensada a partir de uma tecnologia que se desenvolve sobre o julgo da exploração da força de trabalho, da propriedade privada e da exclusão social.

Esse é o ponto em que nos apoiamos para apontar uma limitação da Cad. de Pesq. Interdisc. em Ci-s. Hum-s., Florianópolis, v.14, n.104, p.131-150, jan/jun 2013 
apropriação feita por Dagnino (2004): a tecnologia convencional, enquanto um meio, não é, em essência, imprópria à inclusão social, segmentada, alienante, hierarquizada, eliminadora de trabalho vivo em prol de trabalho morto e monopolizada pelas grandes empresas, mas, sim, a finalidade que as orienta, nesse caso, a valorização do valor. Conforme expõe Marx (2003, p. 503):

\begin{abstract}
A maquinaria, como instrumental que é, encurta o tempo de trabalho; facilita o trabalho; é uma vitória do homem sobre as forças naturais; aumenta a riqueza dos que realmente produzem; mas, com sua aplicação capitalista, gera resultados opostos: prolonga o tempo de trabalho, aumenta sua intensidade, escraviza o homem por meio das forças naturais, pauperiza os verdadeiros produtores.
\end{abstract}

Nesse caso, a solução não está na produção de conhecimento científicotecnológico fora, ou para além, da realidade objetiva, mas, sim, em readequar as finalidades postas, os pores teleológicos, que incidem sobre a tecnologia atual. Sendo assim, a polarização "tecnologia social versus tecnologia convencional" não dá conta de potencializar um processo de construção de uma "tecnologia autogestionária" (DAGNINO, 2004). E, exatamente por conta de sua aplicação capitalista, é que a tecnologia convencional não possui a capacidade necessária para minimizar o exército industrial de reserva e o pauperismo derivados da superexploração da força de trabalho, pois

\begin{abstract}
a redução da jornada cria de início a condição subjetiva para intensificar o trabalho, capacitando o trabalhador a empregar mais força num tempo dado. Quando essa redução se torna legalmente obrigatória, transforma-se a máquina nas mãos do capital em instrumento objetiva e sistematicamente empregado para extrair mais trabalho no mesmo espaço de tempo. É o que se obtém de duas maneiras: aumentando a velocidade da máquina e ampliando a maquinaria a ser vigiada por cada trabalhador, ou seja, seu campo de trabalho (MARX, 2003, p. 470).
\end{abstract}

Mas conceber a solução para o processo de superexploração da força de trabalho a partir de uma tecnologia "não convencional" e desconsiderando a aplicação tecnológica das ciências produzida no e pelo capital, é fragmentar, diluir a potência, em termos de desenvolvimento das condições sociais, inerente ao fator tecnológico, é reduzir a possibilidade de construção das condições necessárias para um enfrentamento contra a aplicação tecnológica capitalista das ciências, fator condicionante para o processo de alienação do trabalhador na produção. 
A atividade do trabalhador, limitada a uma mera abstração da atividade, é
determinada e regulada em todos os aspectos pelo movimento da
maquinaria, e não o inverso. A ciência, que força os membros inanimados
da maquinaria a agirem adequadamente como autômatos por sua
construção, não existe na consciência do trabalhador, mas atua sobre ele
por meio da máquina como poder estranho, como poder da própria
máquina. [...]
A acumulação do saber e da habilidade, das forças produtivas gerais do
cérebro social, é desse modo absorvida no capital em oposição ao trabalho,
e aparece consequentemente como qualidade do capital, mais
precisamente do capital fixo [...] (MARX, 2011, p. 581-582).

Nessa última afirmação, Marx (2011) acena para o fator característico de muitas apropriações críticas, porém limitadas, acerca da tecnologia: a tecnologia, assim como a produção do conhecimento científico, não são frutos do modo de produção capitalista, mas, sim, foram apropriados por esse no intuito de desenvolver as forças produtivas. Nesse caso, toda e qualquer forma de apropriação crítica não deve se dirigir diretamente à tecnologia, enquanto fator alienante e opressor da humanidade, mas, sim, para sua apropriação capitalista, assim sendo, não é a tecnologia que se opõe ao trabalho, mas a sua aplicação capitalista.

Isso significa que não há uma tecnologia "convencional" nem "social", mas, sim, uma aplicação tecnológica capitalista das ciências, a qual organiza, direciona e controla, desde o processo de sua constituição, o conhecimento científico necessário à tecnologia, até a sua aplicação, sob forma de capital fixo implementado constantemente na produção. Nesse caso, tanto o "instrumental" como a "busca dos meios" historicamente acumulados devem ser necessariamente apropriados pelo homem, no intuito de produzir a sua existência a partir de outra perspectiva, diferente daquela submetida à valorização do valor.

\section{Considerações finais}

Convém evidenciarmos a partir das características impostas aos dois termos polarizados alguns elementos contraditórios que permeiam os estudos sobre TS. Diferentemente da TC que deve se opor a TS pelo fato da primeira "não servir" aos propósitos dos empreendimentos solidários autogeridos, Dagnino, Brandão e Novaes (2004) expõem objetivamente que a "teoria da inovação" tem uma contribuição significativa para o desenvolvimento das TS, sendo que o pressuposto concreto dessa teoria é idêntico aquele utilizado para a objetivação das TC necessárias às empresas capitalistas.

Cad. de Pesq. Interdisc. em Ci-s. Hum-s., Florianópolis, v.14, n.104, p.131-150, jan/jun 2013 
A contribuição da teoria da inovação [...] permite entender que a tecnologia - e especialmente, pelas suas características -, a TS só se constitui como tal quando tiver lugar um processo de inovação, um processo do qual emerja um conhecimento criado para atender aos problemas que enfrenta a organização ou grupo de atores envolvidos (DAGNINO; BRANDÃO; NOVAES, 2004, p. 33).

Conforme os autores, a teoria da inovação é o construto teórico-prático que possibilita a constituição de uma "inovação social" ideal para o desenvolvimento dos empreendimentos autogestionários, sendo que a primeira atua como princípio orientador tanto para a TS quanto para a TC, contrariando a própria polarização que os autores fazem.

Em sua crítica ao caráter não científico de uma abordagem "polarizada", Bunge (1987, p. 154) afirma que a polaridade é típica

[...] de uma etapa primitiva do pensamento. A ciência não se limita a procurar polaridades: esforça-se por procurar pontos objetivos (leis) que raras vezes são polares. Mesmo no caso do conflito [contradição] ser real, sua complexidade é tal que extravasa do quadro polar (BUNGE, 1987, p. 154).

Nosso intuito ao trazer tal citação se dá pela necessidade de demonstrarmos que toda e qualquer discussão científica que se constitua a partir do pensamento "polarizado" (bem-mal, certo-errado, etc.) não possui uma capacidade heurística de apreensão do movimento do real, ou seja, não contribui para o desenvolvimento do conhecimento historicamente acumulado. Destarte, nossa análise acerca do que se convencionou chamar de tecnologia social não está subsumida a uma antítese, mas, sim, ao movimento dialético da realidade. Isso significa que ao identificarmos possíveis limitações teóricas concernentes à "tecnologia social", e que, segundo a sua mesma matriz teórica, se contrapõe a uma "tecnologia convencional", pretendemos expor a necessidade de uma apropriação de tecnologia que comporta em sua base epistemológica a sua vinculação direta à ontologia do ser social, conforme Marx e Lukács.

Em suma, torna-se importante frisar que corroboramos com os objetivos colocados para a tecnologia social no que se refere à tentativa de suplantar a necessidade intrínseca ao modo de produção vigente de valorização do valor e contribuir para o desenvolvimento de empreendimentos sociais que proporcionem a produção da existência de maneira mais digna aos seus sujeitos, porém,

Cad. de Pesq. Interdisc. em Ci-s. Hum-s., Florianópolis, v.14, n.104, p.131-150, jan/jun 2013 
discordamos da visão unilateral e polarizada sobre a tecnologia que, conforme pretendemos demonstrar, não contribui para a consecução das finalidades postas em termos de constituição de uma aplicação tecnológica das ciências não orientada à valorização do valor. 


\section{REFERÊNCIAS}

BUNGE, Mario. Epistemologia. 2. ed. São Paulo: T. A. Queiroz, 1987.

DAGNINO, Renato. A tecnologia social e seus desafios. In: Tecnologia social: uma estratégia para o desenvolvimento. Rio de Janeiro: Fundação Banco do Brasil, 2004.

DAGNINO, Renato; BRANDÃO, Flávio C.; NOVAES, Henrique T. Sobre o marco analítico-conceitual da tecnologia social. In: Tecnologia social: uma estratégia para o desenvolvimento. Rio de Janeiro: Fundação Banco do Brasil, 2004.

GUILLERM, Alain; BOURDET, Yvon. Autogestão: uma mudança radical. Rio de Janeiro: Zahar Editores, 1976.

LIMA, Jacob C. (Org.). Ligações perigosas: trabalho flexível e trabalho associado.

São Paulo: Annablume, 2007.

LUKÁCS, György. II Lavoro. In: Per una Ontologia dell' Essere Sociale. Tradução Ivo Tonet. Universidade Federal de Alagoas, s/d.

LUKÁCS, György. Prolegômenos para uma ontologia do ser social. São Paulo: Boitempo, 2010.

MARX, Karl. Capital y Tecnologia - Manuscritos Ineditos (1861-1863). Mexico: Terra Nova, 1980. Disponível em:

$<$ http://www. controversia.com.br/index.php?act=textos\&id=5788>. Acesso em: $18 \mathrm{abr}$. 2013.

MARX, Karl. O Capital: crítica da economia política. Livro I, v. I. Rio de Janeiro: Civilização Brasileira, 1996.

MARX, Karl. O Capital: crítica da economia política. Livro I, v. I. 2. ed. Rio de Janeiro: Civilização Brasileira, 2003.

MARX, Karl. Manuscritos de 1861-1863. Fragmento de A mais-valia relativa acumulação. In: ROMERO, Daniel. Marx e a técnica: um estudo dos manuscritos de 1861-1863. São Paulo: Expressão Popular, 2005. 
MARX, Karl. O Capital: crítica da economia política. Livro III, v. IV. Rio de Janeiro: Civilização Brasileira, 2008.

MARX, Karl. Grundrisse: manuscritos econômicos de 1857-1858: esboços da crítica da economia política. São Paulo: Boitempo/Rio de Janeiro: EdUFRJ, 2011

MINISTÉRIO do Trabalho e Emprego. Desenvolvimento e Disseminação de Conhecimento e Tecnologias Sociais apropriadas à Economia Solidária.

Disponível em: <http://portal.mte.gov.br/ecosolidaria/desenvolvimento-e-disseminacaode-conhecimento-e-tecnologias-sociais-apropriadas-a-economia-solidaria.htm>. Acesso em: 18 abr. 2013.

ROSENBERG, Nathan. Por dentro da caixa-preta: tecnologia e economia. Campinas: EdUNICAMP, 2006. Coleção Clássicos da Inovação.

TAUILE, José Ricardo. Para (re) construir o Brasil contemporâneo: Trabalho, tecnologia e acumulação. Rio de Janeiro: Contraponto, 2001.

VIEIRA PINTO, Alvaro. O conceito de tecnologia. v. I. Rio de Janeiro: Contraponto, 2005.

Artigo:

Recebido em: 14/12/2012

Aceito em: 08/07/2013 